\title{
Differentiation of Bordetella pertussis, B. parapertussis, and B. bronchiseptica by Whole-Cell Protein Electrophoresis and Fatty Acid Analysis
}

\author{
M. VANCANNEYT, * P. VANDAMME, AND K. KERSTERS \\ Laboratorium voor Microbiologie, Faculteit Wetenschappen, \\ University of Ghent, Ghent, Belgium
}

\begin{abstract}
One-dimensional sodium dodecyl sulfate-polyacrylamide gel electrophoresis of whole-cell proteins and gas-liquid chromatography of cellular fatty acids were used to determine chemotaxonomic characteristics of strains belonging to Bordetella pertussis, Bordetella parapertussis, and Bordetella bronchiseptica. Species-specific protein patterns and fatty acid profiles were found. Only $B$. bronchiseptica strains contained 12:0 2OH, 18:1 $\omega 7 \mathrm{c}$, and 19:0 cyclo, and the presence of 10:0 $30 \mathrm{H}$ was a unique feature of $B$. pertussis and B. parapertussis strains. The latter two species were differentiated by the absence of 17:0 cyclo in $B$. pertussis strains. These chemotaxonomic data and the multiple differences in the classical phenotypes of these three species do not correlate with the high DNA homology values. Our findings support the present status of the three taxa as different species and emphasize the importance of a polyphasic approach in bacterial classification.
\end{abstract}

The genus Bordetella is currently composed of six phenotypically distinguishable species, Bordetella avium, Bordetella bronchiseptica, Bordetella parapertussis, Bordetella pertussis, and the recently described species Bordetella hinzii (18) and Bordetella holmesii (25). Three of these species, B. pertussis, B. parapertussis, and B. bronchiseptica, are closely related genomically (23). Mean DNA homology values of 73 to $85 \%$ indicate that these species may be considered different subspecies of a single species $(8,25)$. In contrast, heterogeneity in the restriction profiles of genomic DNAs, as demonstrated by pulsed-field electrophoresis (6), and phenotypic differences support classification of these organisms in separate species. B. pertussis and $B$. parapertussis are both human pathogens, but the latter organism usually causes a milder whooping cough-like disorder. $B$. bronchiseptica is an animal respiratory pathogen which is very rarely isolated from humans (23). In this paper we describe the results obtained with two chemotaxonomic methods that were used to accurately and rapidly characterize these three Bordetella species.

A total of 32 well-characterized strains belonging to $B$. pertussis, B. parapertussis, and B. bronchiseptica were selected for this study. These strains originated from diverse geographic locations, and the B. bronchiseptica strains were isolated from a broad range of hosts (Table 1). Cells were cultivated on plates containing charcoal-blood agar $(5.1 \%$ [wt/vol] charcoal agar [catalog no. CM 119; Oxoid] supplemented with $10 \%$ [vol/vol] horse blood). The cultures were incubated at $35^{\circ} \mathrm{C}$ for 48 h. Following incubation, protein extracts were prepared, and sodium dodecyl sulfate-polyacrylamide gel electrophoresis was performed in a $12 \%$ (wt/vol) polyacrylamide slab gel as described by Pot et al. (14). Levels of similarity between protein patterns were calculated as described by Vauterin and Vauterin (21). We used the Microbial Identification System procedure (Microbial ID, Inc., Newark, Del.) to perform a fatty acid analysis. The procedure of Vandamme et al. (20) was used to harvest the cells, saponify the lipids, methylate the fatty acids, and purify and separate the fatty acid methyl esters by

* Corresponding author. Mailing address: Laboratorium voor Microbiologie, K. L. Ledeganckstraat 35, B-9000 Ghent, Belgium. Phone: 3292645115 . Fax: 3292645346. gas chromatography. Fatty acid methyl ester fingerprints were identified and quantified by using the Microbial Identification System software package (MIS version 3.8) and a calibration mixture containing known standards (Hewlett-Packard Co., Avondale, $\mathrm{Pa}$.).

Protein electrophoresis of whole-cell proteins has been proven to be a sensitive technique for providing information concerning the similarity of strains belonging to the same species in various genera of gram-negative bacteria $(2,15,19,26)$. In general, there is a good correlation between groups identified on the basis of protein patterns and groups identified on the basis of DNA-DNA homology values. Vandamme et al. (18) confirmed this principle for several representatives of the genera Bordetella and Alcaligenes, but the human pathogens $B$. pertussis and $B$. parapertussis were not included in their study. A visual comparison of the overall normalized protein patterns shown in Fig. 1 revealed species-specific patterns for B. pertussis, B. parapertussis, and B. bronchiseptica. Although all of the strains produced a few identical major protein bands, significant qualitative differences among the three taxa were observed. A numerical analysis confirmed our visual interpretation. However, when we used the complete protein patterns for a cluster analysis, several strains exhibited low levels of correlation with other strains belonging to the same species. These obvious anomalies in the numerical comparison results were caused by the presence of dense protein bands with variable molecular weights (ranging from 26,000 to 40,000) in strains belonging to the same species. Variable dense bands that influence the clustering sequences of strains within species have been reported in several other genera. In these taxa, the data for the variable band region reflect interstrain variability and are omitted in order to obtain agreement between protein pattern similarity data and DNA homology data $(2,19)$. Omitting a variable band region (points 190 to 240 on the profile) from the numerical comparison of our protein patterns resulted in clear-cut separation of the three species (Fig. 1), and the correlation coefficients for the members of the Bordetella species were then $\geq 0.89$ for $B$. pertussis, $\geq 0.94$ for $B$. bronchiseptica, and $\geq 0.96$ for $B$. parapertussis. We obtained a correlation coefficient of 0.92 when we compared $B$. bronchiseptica and $B$. parapertussis. Both of these species were linked to $B$. pertussis at a correlation coefficient value of 0.73 . The repro- 
TABLE 1. Bordetella strains studied

\begin{tabular}{|c|c|c|c|}
\hline Species & Strain $^{a}$ & Designation as received ${ }^{a}$ & Source \\
\hline \multirow{10}{*}{ B. bronchiseptica } & LMG $1232^{\mathrm{T} b}$ & NCTC $452^{\mathrm{T}}$ & Dog lung \\
\hline & LMG 1807 & NCTC 455 & Ferret trachea (1913) \\
\hline & LMG 1809 & NCTC 8751 & Guinea pig lung \\
\hline & LMG 1811 & NCTC 10540 & Whooping cough-like disease (United States, 1949) \\
\hline & LMG $3521 \mathrm{t} 1$ & Hinz 40-81 & Turkey trachea (Germany) \\
\hline & LMG 3531 & NCTC 458 & Human sputum (1913) \\
\hline & LMG 3535 & CCM 6048 & Rabbit \\
\hline & LMG 3538 & CCM 6155 & Dog \\
\hline & LMG 3542 & CCUG 7865 & Human nasopharynx (Borås, Sweden, 1979) \\
\hline & LMG 14526 & CCUG 31300 & \\
\hline \multirow[t]{10}{*}{ B. parapertussis } & LMG 1816 & NCTC 7385 & \\
\hline & LMG 1818 & NCTC 10853 & Cough plate \\
\hline & LMG 1819 & CNCTC Hpp 5/59 & \\
\hline & LMG 1820 & NCTC 10520 & \\
\hline & LMG 1825 & NCTC 10525 & \\
\hline & LMG 1827 & CNCTC Hpp 1/58 & Human \\
\hline & LMG 1833 & NCTC 8250 & \\
\hline & LMG $14449^{\mathrm{T}}$ & CCUG $413^{\mathrm{T}}$ & Whooping cough \\
\hline & LMG 14450 & CCUG $882 \mathrm{~A}$ & \\
\hline & LMG 14451 & CCUG 4099 & Human nasopharynx (Göteborg, Sweden, 1974) \\
\hline \multirow{12}{*}{ B. pertussis } & LMG 14452 & CCUG 699 & Human nasopharynx (Göteborg, Sweden, 1970) \\
\hline & LMG 14453 & CCUG 9818 & Human nasopharynx (Göteborg, Sweden, 1980) \\
\hline & LMG 14454 & CCUG 17283 & \\
\hline & LMG $14455^{\mathrm{T}}$ & CCUG $30873^{\mathrm{T}}$ & \\
\hline & LMG 14522 & CCUG 32523 & Human (Stockholm, Sweden, 1994) \\
\hline & LMG 15140 & CCUG 13475 & \\
\hline & LMG 15141 & CCUG 15610 & \\
\hline & LMG 15142 & CCUG 23702 & Human (Växjö, Sweden, 1988) \\
\hline & LMG 15585 & CHMC 237.731 & Human (Cincinnati, Ohio) \\
\hline & LMG 15586 & CHMC 212-422 & Human (Cincinnati, Ohio) \\
\hline & LMG 15587 & CHMC 266-1003 & Human (Cincinnati, Ohio) \\
\hline & LMG 15589 & CHMC 244-889 & Human (Cincinnati, Ohio) \\
\hline
\end{tabular}

${ }^{a}$ CCM, Czechoslovak Collection of Microorganisms, Brno, Czech Republic; CCUG, Culture Collection of the University of Göteborg, Department of Clinical Bacteriology, University of Göteborg, Göteborg, Sweden; CHMC, Children's Hospital Medical Center, Cincinatti, Ohio; CNCTC, Czechoslovak National Collection of Type Cultures, Institute of Hygiene and Epidemiology, Prague, Czech Republic; Hinz, K. H. Hinz, Klinik für Geflügel, der Tierärztlichen Hochschule Hannover, Hannover, Germany; LMG, Culture Collection of the Laboratorium voor Microbiologie, University of Ghent, Ghent, Belgium; NCTC, National Collection of Type Cultures, Central Public Health Laboratory, London, United Kingdom.

${ }^{b} \mathrm{~T}=$ type strain.

ducibility of the method was very good; the correlation coefficients for duplicate protein patterns were $\geq 0.96$.

The average fatty acid methyl ester compositions of $B$. bronchiseptica, $B$. parapertussis, and $B$. pertussis were also investigated (Table 2). The standard deviations indicated that there were only minor intraspecific differences. The fatty acids present in all of the strains which we studied were 14:0, 15:0, $16: 0,16: 1 \omega 7 \mathrm{c}, 17: 0,18: 0$, and summed feature 3. Summed feature 3 comprised two fatty acids, $16: 1$ iso and $14: 03 \mathrm{OH}$, which could not be distinguished by the Microbial Identification System. Vandamme et al. (18) and Weyant et al. (25) reported that the peak designated summed feature 3 probably corresponds to $14: 03 \mathrm{OH}$. An examination of the cellular fatty acid profiles revealed that the three taxa could be clearly distinguished. B. bronchiseptica strains were distinguished from all other strains by small but significant amounts of fatty acids 12:0 $2 \mathrm{OH}, 19: 0$ cyclo $\omega 8 \mathrm{c}$, and summed feature 7 . The results of a study performed by Weyant et al. (25) indicated that summed feature 7, which comprises three isomers of $18: 1$, is probably $18: 1 \omega 7 \mathrm{c}$. Furthermore, $B$. bronchiseptica lacked the hydroxy fatty acid 10:0 $30 \mathrm{H}$, which was present in considerable amounts in $B$. pertussis and $B$. parapertussis. The latter two species were easily differentiated by the absence of $17: 0$ cyclo in $B$. pertussis strains and the much higher level of $16: 1 \omega 7 \mathrm{c}$ in these strains.

The fatty acid compositions of the Bordetella species consid- ered in this study have been determined previously by other workers $(4,5,11,18,25)$. Jantzen et al. (5) and Weyant et al. (25) studied representatives of all three species. Jantzen et al. (5) confirmed that the three Bordetella species could be differentiated easily. However, these authors indicated that all of the fatty acids detected except 17:0 cyclo were present in at least trace amounts in all three species. Using the standardized procedure, we identified additional qualitative differences in the fatty acid profiles which may be used as diagnostic markers. Only B. bronchiseptica strains contained 12:0 2OH, 18:1 $\omega 7 \mathrm{c}$ (summed feature 7), and 19:0 cyclo, and 10:0 3OH was found only in B. pertussis and B. parapertussis strains (Table 2). Jantzen et al. (5) also indicated that $B$. pertussis strains produced small amounts of $\mathrm{C}_{11}, \mathrm{C}_{13}$, and $\mathrm{C}_{15}$ 3-hydroxy acids. Our results, which were based on alkaline (not acidic) release of fatty acids, showed that only the type strain of $B$. pertussis contained a significant amount of 11:0 $3 \mathrm{OH}$ (Table 2), and the other two fatty acids were not detected.

Weyant et al. (25) determined the cellular fatty acid compositions of only two or three strains of each of the three species. The low numbers of strains, which were isolated from a restricted geographic area, yielded limited data concerning the variability of the fatty acid compositions of the strains of these species. Therefore, some of the fatty acids which were used to differentiate their strains may not be useful as general, species-specific, diagnostic markers. Our data, which were 


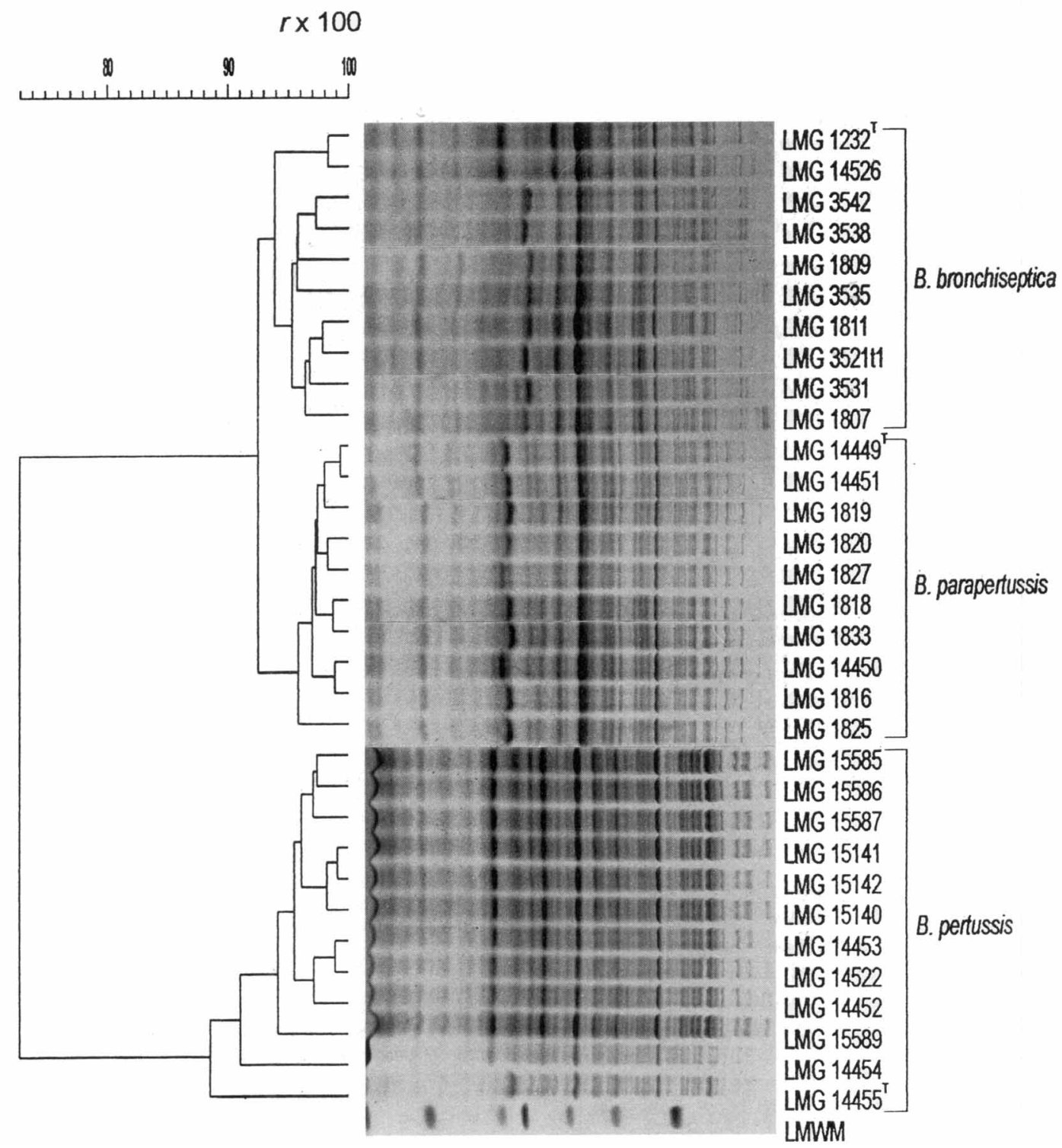

FIG. 1. Normalized photograph of sodium dodecyl sulfate-polyacrylamide protein electropherograms for the strains studied and corresponding dendrogram based on an average-linkage cluster analysis of correlation coefficients ( $r$ values). The molecular weight markers used (track LMWM) were (from left to right) lysozyme (molecular weight, 14,500$)$, trypsin inhibitor $(20,100)$, carbonic anhydrase $(29,000)$, glyceraldehyde-3-phosphate dehydrogenase $(36,000)$, egg albumin $(45,000)$, bovine albumin $(66,000)$, and $\beta$-galactosidase $(116,000)$.

based on a larger and more diverse set of strains, showed that 15:0 and 17:0 fatty acids were present in all three species and not only in B. parapertussis as suggested by Weyant et al. (25). Moreover, 12:0 3OH fatty acid occurred in some of the strains of both B. bronchiseptica and B. pertussis, not only in B. pertussis strains.

In two other studies $(11,18)$ focusing on avian isolates the researchers included only the broad-host-range pathogen $B$. bronchiseptica. These authors obtained qualitatively very similar patterns compared with our data. Jackwood et al. (4) examined $B$. bronchiseptica and $B$. parapertussis strains. An important qualitative difference between the data of these authors and our data was the presence of significant amounts of 18:1 in B. parapertussis in their study. Obviously, in all of these studies quantitative differences in fatty acid contents may have been due to different incubation conditions (3). Finally, fatty acid fingerprint data obtained from previous studies demonstrated that $B$. bronchiseptica, $B$. parapertussis, and $B$. pertussis can be easily distinguished from $B$ avium, $B$. hinzii, and $B$. holmesii by their lack of significant amounts of 14:0 $2 \mathrm{OH}(11$, $18,25)$. This confirms the importance of hydroxy fatty acids as taxonomic markers in the classification of gram-negative bacteria, as demonstrated previously in several studies $(12,15,17$, 28).

Both of the chemotaxonomic methods which we used allowed us to characterize and identify three clearly different taxa, B. bronchiseptica, B. parapertussis, and B. pertussis, which suggests that species rank is justified for each of these taxa. Indeed, in general, strains belonging to the same species exhibit only minor quantitative differences in their fatty acid profiles $(10,24)$, and we and other workers $(4,11,18,25)$ have found significant qualitative differences among these three 
TABLE 2. Fatty acid compositions of the species investigated

\begin{tabular}{|c|c|c|c|}
\hline \multirow[b]{2}{*}{ Fatty acid ${ }^{a}$} & \multicolumn{3}{|c|}{$\%$ of total fatty acids } \\
\hline & $\begin{array}{l}\text { B. bronchiseptica } \\
\text { (10 strains) }\end{array}$ & $\begin{array}{l}\text { B. parapertussis } \\
\text { (10 strains) }\end{array}$ & $\begin{array}{l}\text { B. pertussis } \\
\text { (12 strains) }\end{array}$ \\
\hline 10:0 3OH & $\mathrm{ND}^{\prime \prime}$ & $2.5 \pm 0.2(10)^{c}$ & $2.4 \pm 0.9(12)$ \\
\hline $12: 0$ & $\operatorname{Tr}(8)$ & ND & ND \\
\hline $12: 02 \mathrm{OH}$ & $3.2 \pm 0.4(10)$ & ND & ND \\
\hline $12: 03 \mathrm{OH}$ & $\operatorname{Tr}(9)$ & ND & $\operatorname{Tr}(8)$ \\
\hline $14: 0$ & $6.4 \pm 0.2(10)$ & $6.5 \pm 1.0(10)$ & $4.4 \pm 0.4(12)$ \\
\hline $15: 0$ & $1.1 \pm 0.6(10)$ & $1.0 \pm 0.3(10)$ & $2.0 \pm 1.1(12)$ \\
\hline $15: 1 \omega 6 \mathrm{c}$ & ND & ND & $1.1 \pm 0.9(11)$ \\
\hline $16: 0$ & $36.0 \pm 0.7(10)$ & $40.9 \pm 1.7(10)$ & $30.6 \pm 4.4(12)$ \\
\hline $16: 1 \omega 5 \mathrm{c}$ & $\operatorname{Tr}(7)$ & $\operatorname{Tr}(3)$ & ND \\
\hline $16: 1 \omega 7 \mathrm{c}$ & $2.8 \pm 0.8(10)$ & $2.8 \pm 1.7(10)$ & $39.9 \pm 1.0(12)$ \\
\hline $16: 03 \mathrm{OH}$ & $\operatorname{Tr}(9)$ & $\operatorname{Tr}(3)$ & ND \\
\hline $17: 0$ & $1.7 \pm 0.7(10)$ & $2.3 \pm 1.1(10)$ & $3.2 \pm 1.8(12)$ \\
\hline 17:0 cyclo & $33.5 \pm 2.2(10)$ & $34.4 \pm 2.7(10)$ & ND \\
\hline $18: 0$ & $2.2 \pm 0.4(10)$ & $3.5 \pm 1.4(10)$ & $5.7 \pm 1.9(12)$ \\
\hline $18: 1 \omega 9 \mathrm{c}$ & ND & ND & $\operatorname{Tr}(6)$ \\
\hline 19:0 cyclo $\omega 8 \mathrm{c}$ & $1.1 \pm 0.4(10)$ & ND & ND \\
\hline Summed feature 3 & $8.0 \pm 1.1(10)$ & $5.9 \pm 0.9(10)$ & $8.5 \pm 1.8(12)$ \\
\hline Summed feature 6 & ND & ND & $1.1 \pm 0.5(10)$ \\
\hline Summed feature 7 & $2.2 \pm 1.4(10)$ & ND & ND \\
\hline
\end{tabular}

a 11:0 3OH Fatty acid was found in B. pertussis LMG $14455^{\mathrm{T}}$ at a level of $1.6 \%$, and 19:0 iso fatty acid was detected in B. bronchiseptica LMG 1811 at a level of $0.5 \%$. Summed features represent groups of two or three fatty acids which could not be separated under the gas chromatographic conditions used in this study. Summed feature 3 contained 14:0 $3 \mathrm{OH}$ or 16:1 iso or both; summed feature 6 contained 18:0 anteiso or 18:2 $\omega 6,9 \mathrm{c}$ or both; and summed feature 7 contained $18: 1 \omega 7 \mathrm{c}, 18: 1 \omega 9 \mathrm{t}$, or $18: 1 \omega 12 \mathrm{t}$ or any combination of these fatty acids.

${ }^{b} \mathrm{ND}$, not detected.

Mean \pm standard deviation. The numbers in parentheses are the numbers of strains which contained the fatty acid.

taxa. In addition, the differences in the protein patterns, especially the differences between $B$. pertussis and the other two species, were considerable and cannot be compared with differences that occur between electrophoretic types within a single species, as has been reported previously for $B$. hinzii and B. avium (18). The chemotaxonomic data described above corroborate the different phenotypic and immunological characteristics of the three species $(7,13)$ and may reflect the speciesspecific profiles obtained after macrorestriction digestion of the DNAs (6). However, our data contradicted the unexpectedly high DNA homology values obtained with these species $(8,18,25)$. When genera representing the different lineages in the Proteobacteria are considered, it is very uncommon to find closely related strains that exhibit such a high level of phenotypic diversity, including chemotaxonomic diversity. In general, we believe that the standard for delineating species defined by Wayne et al. (22) is a good standard. However, the 70\% DNA homology rule is also unsatisfactory in many genera, including the genera Acinetobacter (1), Aeromonas (9), Capnocytophaga (16), and Comamonas (27); in these genera different genotypic groups exhibit no homology or considerably less than $70 \%$ DNA homology and cannot be distinguished by phenotypic characteristics. We strongly believe that delineation of any taxonomic unit should be based on a consensus among genotypic, chemotaxonomic, and phenotypic data, and therefore, in this exceptional situation, we consider $B$. pertussis, $B$. parapertussis, and $B$. bronchiseptica separate species.

We thank the depositors of strains listed in Table 1. We also thank Urbain Torck and Dirk Dewettinck for performing the protein electrophoresis.

P.V. is indebted to the National Fund for Scientific Research (Belgium) for a position as a postdoctoral research fellow. K.K. is indebted to the Fund for Medical Scientific Research, Belgium, for research and personnel grants. Part of this research was performed within the framework of CEC contract BIO2-CT94-3098.

\section{REFERENCES}

1. Bouvet, P. J., and S. Jeanjean. 1986. Delineation of new proteolytic genomic species in the genus Acinetobacter. Res. Microbiol. 140:291-299.

2. Costas, M. 1992. Classification, identification, and typing of bacteria by the analysis of their one-dimensional polyacrylamide gel electrophoretic protein patterns, p. 351-408. In A. Chambrach, M. J. Dunn, and B. J. Radola (ed.), Advances in electrophoresis, vol. 5. VCH Verlagsgesellschaft, Weinheim, Germany.

3. Cronan, J. E. 1968. Phospholipid alterations during growth of Escherichia coli. J. Bacteriol. 95:2054-2061.

4. Jackwood, M. W., M. Sasser, and Y. M. Saif. 1986. Contribution to the taxonomy of the turkey coryza agent: cellular fatty acid analysis of the bacterium. Avian Dis. 30:172-178.

5. Jantzen, E., E. Knudsen, and R. Winsnes. 1982. Fatty acid analysis for differentiation of Bordetella and Brucella species. Acta Pathol. Microbiol. Immunol. Scand. Sect. B 90:353-359.

6. Khattak, M. N., and R. C. Matthews. 1993. Genetic relatedness of Bordetella species as determined by macrorestriction digests resolved by pulsed-field gel electrophoresis. Int. J. Syst. Bacteriol. 43:659-664.

7. Khelef, N., B. Danve, M. J. Quentin-Millet, and N. Guiso. 1993. Bordetella pertussis and Bordetella parapertussis: two immunologically distinct species. Infect. Immun. 61:486-490.

8. Kloos, W. E., N. Mohapatra, W. J. Dobrogosz, J. W. Ezzell, and C. R. Manclark. 1981. Deoxyribonucleotide sequence relationships among Bordetella species. Int. J. Syst. Bacteriol. 31:173-176.

9. Kuijper, E. J., A. G. Steigerwalt, B. S. C. I. M. Schoenmakers, M. F. Peeters, H. C. Zanen, and D. J. Brenner. 1989. Phenotypic characterization and DNA relatedness in human fecal isolates of Aeromonas spp. J. Clin. Microbiol. 27:132-138.

10. Miller, L., and T. Berger. 1985. Bacteria identification by gas chromatography of whole-cell fatty acids. Hewlett-Packard Gas Chromatography Application Note 228-41. Hewlett-Packard Co., Palo Alto, Calif.

11. Moore, C. J., H. Mawhinney, and P. J. Blackall. 1987. Differentiation of Bordetella avium and related species by cellular fatty acid analysis. J. Clin. Microbiol. 25:1059-1062.

12. Oyaizu, H., and K. Komagata. 1983. Grouping of Pseudomonas species on the basis of cellular fatty acid composition and the quinone system with special reference to the existence of 3-hydroxy fatty acids. J. Gen. Appl. Microbiol. 29:17-40.

13. Pittman, M. 1984. Genus Bordetella Moreno-Lopez 1952 , $178^{\mathrm{AL}}$, p. 388-393. In N. R. Krieg and J. G. Holt (ed.), Bergey's manual of systematic bacteriology, vol. 1. The Williams \& Wilkins Co., Baltimore.

14. Pot, B., P. Vandamme, and K. Kersters. 1993. Analysis of electrophoretic whole-organism protein fingerprints, p. 493-521. In M. Goodfellow and A. G. O'Donnell (ed.), Chemical methods in prokaryotic systematics. J. Wiley and Sons, Chichester, United Kingdom.

15. Segers, P., M. Vancanneyt, B. Pot, U. Torck, B. Hoste, D. Dewettinck, E. Falsen, K. Kersters, and P. De Vos. 1994. Classification of Pseudomonas diminuta Leifson and Hugh 1954 and Pseudomonas vesicularis Büsing, Döll, and Freytag 1953 in Brevundimonas gen. nov. as Brevundimonas diminuta comb. nov. and Brevundimonas vesicularis comb. nov., respectively. Int. J. Syst. Bacteriol. 44:499-510.

16. Speck, H., R. M. Kroppenstedt, and W. Mannheim. 1987. Genomic relationships and species differentiation in the genus Capnocytophaga. Zentralbl Bakteriol. Parasitenkd. Infektionskr. Hyg. Abt. 1 Orig. Reihe A 266:390-402.

17. Suzuki, K., M. Goodfellow, and A. G. O'Donnell. 1993. Cell envelopes and classification, p. 195-238. In M. Goodfellow and A. G. O'Donnell (ed.), Handbook of new bacterial systematics. Academic Press, London.

18. Vandamme, P., J. Hommez, M. Vancanneyt, M. Monsieurs, B. Hoste, B. Cookson, C. H. Wirsing von König, K. Kersters, and P. J. Blackall. 1995. Bordetella hinzii sp. nov., isolated from poultry and humans. Int. J. Syst. Bacteriol. 45:37-45.

19. Vandamme, P., B. Pot, E. Falsen, K. Kersters, and J. De Ley. 1990. Intraand interspecific relationships of veterinary campylobacters revealed by numerical analysis of electrophoretic protein profiles and DNA:DNA hybridizations. Syst. Appl. Microbiol. 13:295-303.

20. Vandamme, P., M. Vancanneyt, B. Pot, L. Mels, B. Hoste, D. Dewettinck, L. Vlaes, C. Van den Borre, R. Higgins, J. Hommez, K. Kersters, J.-P. Butzler, and H. Goossens. 1992. Polyphasic taxonomic study of the emended genus Arcobacter with Arcobacter butzleri comb. nov. and Arcobacter skirrowii sp. nov., an aerotolerant bacterium isolated from veterinary specimens. Int. J. Syst. Bacteriol. 42:344-356.

21. Vauterin, L., and P. Vauterin. 1992. Computer-aided objective comparison of electrophoresis patterns for grouping and identification of microorganisms. Eur. Microbiol. 1:37-41.

22. Wayne, L. G., D. J. Brenner, R. R. Colwell, P. A. D. Grimont, O. Kandler, M. 1. Krichevsky, L. H. Moore, W. E. C. Moore, R. G. E. Murray, E. Stackebrandt, M. P. Starr, and H. G. Trüper. 1987. Report of the Ad Hoc 
Committee on Reconciliation of Approaches to Bacterial Systematics. Int. J. Syst. Bacteriol, 37:463-464.

23. Weiss, A. A. 1992 . The genus Bordetella, p. 2530-2543. In A. Balows, H. G. Trüper, M. Dworkin, W. Harder, and K.-H. Schleifer (ed.), The prokaryotes, 2nd ed., vol. 2. Springer-Verlag, Berlin.

24. Welch, D. F. 1991. Applications of cellular fatty acid analysis. Clin. Microbiol. Rev. 4:422-438.

25. Weyant, R. S., D. G. Hollis, R. E. Weaver, M. F. M. Amin, A. G. Steigerwalt S. P. O'Connor, A. M. Whitney, M. I. Daneshvar, C. W. Moss, and D. J. Brenner. 1995. Bordetella holmesii sp. nov., a new gram-negative species associated with septicemia. J. Clin. Microbiol. 33:1-7.

26. Willems, A., M. Goor, S. Thielemans, M. Gillis, K. Kersters, and J. De Ley. 1992. Transfer of several phytopathogenic Pseudomonas species to Ac- idovorax as Acidovorax avenae subsp. avenae subsp. nov., comb. nov., Acidovorax avenae subsp. citnulli, Acidovorax avenae subsp. cattleyae, and Acidovorax konjaci. Int. J. Syst. Bacteriol. 42:107-119.

27. Willems, A., B. Pot, E. Falsen, P. Vandamme, M. Gillis, K. Kersters, and J. De Ley. 1991. Polyphasic taxonomic study of the emended genus Comamonas: relationship to Aquaspirillum aquaticum, E. Falsen group 10, and other clinical isolates. Int. J. Syst. Bacteriol, 41:427-444.

28. Yabuuchi, E., I. Yano, H. Oyaizu, Y. Hashimoto, T. Ezaki, and H. Yamamoto. 1990. Proposals of Sphingomonas paucimobilis gen. nov. and comb. nov., Sphingomonas parapaucimobilis sp. nov., Sphingomonas yanoikuyae sp. nov., Sphingomonas adhaesiva sp. nov., Sphingomonas capsulata comb. nov., and two genospecies of the genus Sphingomonas. Microbiol. Immunol. 34:99-110. 